HNO 2012 - 60:905-905

DOI 10.1007/s00106-012-2603-1

Online publiziert: 30 . September 2012

c) Springer-Verlag Berlin Heidelberg 2012

F. Ihler ${ }^{1} \cdot$ R. Laskawi ${ }^{1} \cdot$ C. Matthias ${ }^{1} \cdot$ H.H. Rustenbeck ${ }^{2} \cdot$ M. Canis $^{1}$

${ }^{1}$ Klinik und Poliklinik für Hals-Nasen-Ohrenheilkunde, Universitätsmedizin Göttingen

${ }^{2}$ Abteilung für Diagnostische Radiologie, Universitätsmedizin Göttingen

\title{
Erratum zu
}

\section{„Einsatz von Botulinum Toxin A nach mikrovaskulärem ALT-Lappen bei einem Patienten mit Zungen- und Mundbodenkarzinom"}

\author{
HNO 60:524-527 http://www.dx.doi.org/ \\ DOI 10.1007/s00106-011-2476-8
}

In der HTML-Version des o. g. Beitrags wurde leider der Beitragstitel in Deutsch und Englisch falsch wiedergegeben. Wir bitten darum, statt des dort genannten deutschen Titels „Botulinumtoxin A gegen Hypersalivation“ den Titel „Einsatz von Botulinum Toxin A nach mikrovaskulärem ALT-Lappen bei einem Patienten mit Zungen- und Mundbodenkarzinom“ zu berücksichtigen und den Fehler zu entschuldigen. Der englische Titel muss statt des dort genannten Titels „Botulinum toxin A for drooling“ lauten: „Botulinum toxin A after microvascular ALT flap in a patient with squamous cell carcinoma of the tongue".

Die Redaktion

\section{Korrespondenzadresse}

PD Dr. M. Canis

Klinik und Poliklinik

für Hals-Nasen-Ohrenheilkunde Universitätsmedizin Göttingen Robert-Koch-Str. 40, 37099 Göttingen martin.canis@med.uni-goettingen.de 